\title{
Dissipation of Cypermethrin in Bean and Cauliflower
}

\author{
Nilufar Nahar ${ }^{1}$, Mohammad Motaher Hossain ${ }^{1,2}$, Md. Nashir Uddin Al Mahmud ${ }^{1}$, Mohammad Shoeb ${ }^{1}$, Gulshan Ara \\ Latifa $^{2}$ and Kamal Humayun Kabir ${ }^{3}$ \\ ${ }^{1}$ Department of Chemistry, Dhaka University, Dhaka, Bangladesh \\ ${ }^{2}$ Department of Zoology, Dhaka University, Dhaka, Bangladesh \\ ${ }^{3}$ Entomology Division, Bangladesh Agricultural Research Institute, Gazipur, Bangladesh
}

(Received: 7 December 2015; Accepted: 24 January 2016)

\section{Introduction}

Cypermethrin [(RS)- $\alpha$-cyano-3-phenoxybenzyl (1RS, 3RS; 1RS, 3RS)-3-(2, 2-dichlorovinyl) -2,2-dimethylcyclopropanecarboxylate] is one of the synthetic pyrethroids which have become most important insecticides in wide-scale use. Pyrethroids were reported to have relatively low toxicity as compared to organochlorine, organophosphorous, and carbamates pesticides ${ }^{1}$ and their metabolites are also low toxic or non toxic compared with parent pyrethroid compounds $^{2}$. These are effective against the pests which are registrant to other group pesticides ${ }^{3}$ and account onethird of world insecticides use $\mathrm{e}^{4}$ despite their high cost.

The vegetables are low in fat, high in dietary fibers; contain minerals and vitamins, possessing a very high nutritional density. But repeated applications and over doses of pesticides in the vegetable cultivation by the farmers make these unsafe and health hazardous for every day consumption. It is necessary to monitor and assess of the pesticide contamination in vegetables samples. In continuation of our work on vegetables, we are now reporting dissipation patterns of cypermethrin in cauliflower (Brassica oleracea var.) and bean (Phaseolus vulgaris) and their safe harvesting periods.

\section{Experimental}

The experiments was conducted at the experimental field of Bangladesh Agricultural Research Institute, Joydebpur, Gazipur situated at latitude $23^{\circ} 46^{\prime \prime} \mathrm{N}$ and longitude $90^{\circ} 23^{\prime \prime}$ $\mathrm{E}$ with an elevation of 8.45 meter the sea level. Seeds were sown in the nursery bed at research field of Entomology Division, Bangladesh Agricultural Research Institute, Gazipur. The plants were lightly irrigated regularly for ensuring proper growth and development of the seedlings. Forty days old seedlings were transplanted in the well prepared experimental plot in $28^{\text {th }}$ October 2012. "Ripcord10-EC" (100 g cypermethrin per liter) was sprayed at recommended dose of $(1 \mathrm{~mL}$ in $1 \mathrm{~L}$ water $=100 \mathrm{mg}$ cypermethrin in $1 \mathrm{~kg}$ water) in experimental bed (cauliflower at 2 December \& bean at 18 December, 2012). Before spraying, blank/control samples were collected. Then two replicate samples from each bed were collected at the intervals of 0 (after 2 hours of spraying), 1, 3, 5, 7, 10 and 15 days after spraying. They were kept in a freezer by wrapping with clean polythene bag (jeep-lock) at temperature below $-20^{\circ} \mathrm{C}$.
Edible part of each vegetable sample (250 g) was cut into small pieces and homogenized by means of a kitchen blender. $20 \mathrm{~mL}$ ethyl acetate was added to $10 \mathrm{~g}$ homogenized sample in $50 \mathrm{~mL}$ Teflon tube and shaken for 1 minute by hand \& vortexed for $1 \mathrm{~min}$. Anhydrous $\mathrm{MgSO}_{4}$ (6 g) \& $1.5 \mathrm{~g} \mathrm{NaCl}$ were added and vortexed for $1 \mathrm{~min}$ and then centrifuged for 5 minutes at $4000 \mathrm{rpm}$. $10 \mathrm{~mL}$ supernatant was taken in $100 \mathrm{~mL}$ round bottomed flask, evaporated in rotary evaporator and then reconstituted in nhexane $(2 \mathrm{~mL})$. A glass column $(40 \mathrm{~cm}$ long and $12 \mathrm{~mm}$ internal diameter) was packed with a $10.5 \mathrm{~g}$ mixture of aluminum oxide, florisil and charcoal (10:10:1) in $n-$ hexane. The column was equilibrated with $50 \mathrm{~mL}$-hexane and then the sample extract in $\mathrm{n}$-hexane $(2 \mathrm{~mL})$ was applied to the column. The column was washed with $20 \mathrm{~mL}$ of $\mathrm{n}-$ hexane and eluted with $100 \mathrm{~mL}$ of dichloromethane at the rate of $1 \mathrm{~mL} \mathrm{~min}^{-1}$. The eluent was concentrated to dryness by a rotary vacuum evaporator and re-dissolved the residue in $2 \mathrm{~mL}$ of $\mathrm{n}$-hexane and analyzed by GC-ECD.

A Shimadzu 17A GC system equipped with Electron Capture Detector was used for analysis. The injector \& detector temperatures were $280{ }^{\circ} \mathrm{C} \& 300{ }^{\circ} \mathrm{C}$. Separations were performed on HP-5MS quartz capillary column (30 m $\times 250 \mu \mathrm{m}$ i.d. and $0.25 \mu \mathrm{m}$ film thickness), nitrogen was used as a carrier gas and flow rate was $1.0 \mathrm{~mL} \mathrm{~min}{ }^{-1}$. Samples were injected manually in split-less split mode and injection volume was $1 \mu \mathrm{L}$. The oven temperature was programmed as initial temperature of $120{ }^{\circ} \mathrm{C}$ held for 2 min, increased at $10{ }^{\circ} \mathrm{C} \mathrm{min}{ }^{-1}$ to $270{ }^{\circ} \mathrm{C}$; held for $1 \mathrm{~min}$. and then another increased at $2{ }^{\circ} \mathrm{C} \mathrm{min}{ }^{-1}$ to $290{ }^{\circ} \mathrm{C}$; held for $3 \mathrm{~min}$.

\section{Results and Discussion}

The residual level of cypermethrin in bean and cauliflower was analyzed by GC-ECD using external standard calibration method. The linear calibration curves over six calibration levels, from $0.025-2.0 \mathrm{mg} \mathrm{L}^{-1}$ were constructed by the direct injection of calibration standards. The linearities were excellent with a correlation coefficient of $\mathrm{r}^{2}$ $=0.998$. The unnecessary compounds interfering with the analytes were examined by comparing the chromatograms of the standard, blank sample and spiked sample. There were no interference peaks at the retention time of cypermethrin. The LOD (limit of detection; Signal to noise ration, 3:1) and

*Author for correspondence. e-mail: nilufarnahar@yahoo.com 
LOQ (limit of quantification; Signal to noise ration, 10:1) were found to be $0.01 \& 0.033 \mathrm{mg} \mathrm{kg}^{-1}$, respectively. The recovery experiments were performed in three replicates at 2 spiking levels $\left(0.25 \& 1.0 \mathrm{mg} \mathrm{kg}^{-1}\right)$. The spiked samples were left to stand for $2 \mathrm{~h}$ to allow for the adsorption of pesticide onto the samples. The recoveries were $76-107 \%$ with RSD $\leq 13 \%$ which were in accordance with Codex Alimentarius ${ }^{5}$. Residual amounts of cypermethrin in all the analyzed samples in which recommended doses sprayed are presented in Table 1. The pesticide was degraded with time following first order kinetics (Fig. 1). The residue concentration of cypermethrin in bean was found to be $3.8 \pm$ 0.53 and $0.32 \pm 0.01 \mathrm{mg} \mathrm{kg}^{-1}$ at 0 day (2 hours after spray) and at 15 days after application, respectively. Residue in cauliflower was found to be $6.7 \pm 1.8$ at 0 and $0.12 \pm 0.01$ $\mathrm{mg} \mathrm{kg}^{-1}$ at 15 days, respectively after application. Residue of cypermethrin in bean and cauliflower was found to be below MRL on 10 and 7 days after application, respectively. The results are in agreement with the findings of Chai et al (2009) $)^{6}$ and Nahar et al. (2012) ${ }^{7}$ where dissipation of cypermethrin was studied in green mustard and tomato, respectively.

Table 1. Cypermethrin residues in vegetables matrix at different time intervals following its application

\begin{tabular}{|c|c|c|c|}
\hline Sample & Day after spraying & Bean $\left[(\mathrm{Av} . \pm \mathrm{SD}), \mathrm{mg} \mathrm{kg}^{-1}\right]$ & Cauliflower [(Av. $\left.\pm \mathrm{SD}), \mathrm{mg} \mathrm{kg}^{-1}\right]$ \\
\hline Control & - & Not detected & Not detected \\
\hline \multirow{5}{*}{ Day } & 0 & $3.77 \pm 0.53$ & $6.68 \pm 1.86$ \\
\cline { 2 - 4 } & 1 & $2.69 \pm 0.19$ & $2.94 \pm 0.16$ \\
\cline { 2 - 4 } & 3 & $1.13 \pm 0.08$ & $1.72 \pm 0.05$ \\
\cline { 2 - 4 } & 5 & $0.94 \pm 0.11$ & $1.12 \pm 0.04$ \\
\cline { 2 - 4 } & 7 & $0.89 \pm 0.06$ & $0.67 \pm 0.05$ \\
\cline { 2 - 4 } & 10 & $0.45 \pm 0.11$ & $0.17 \pm 0.03$ \\
\hline
\end{tabular}
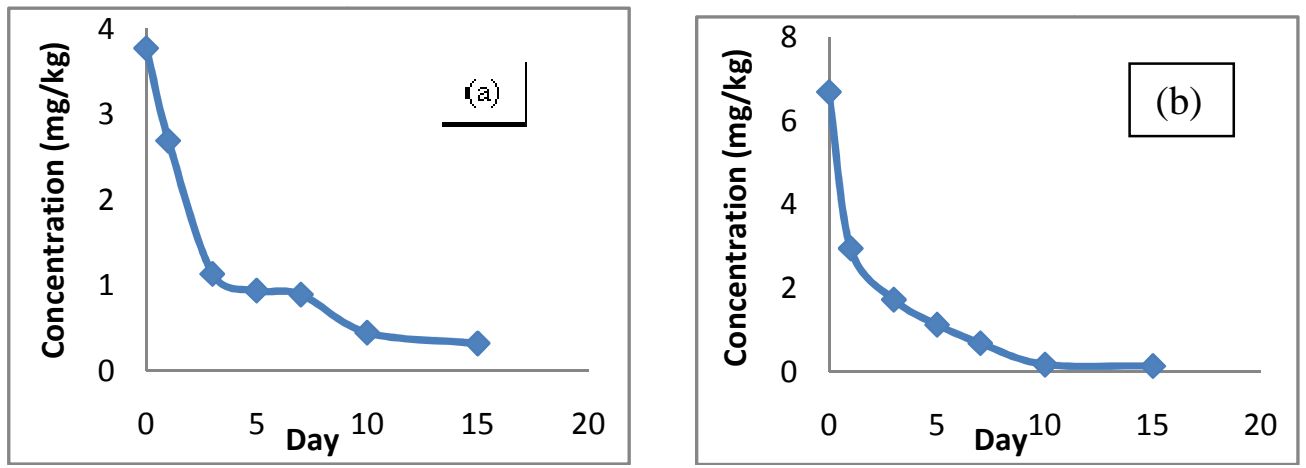

Fig 1. Dissipation curves of cypermethrin in (a) bean and (b) cauliflower

\section{Conclusion}

Farmers use cypermethrin for bean and cauliflower very frequently, even twice a day and harvest crop immediately after pesticide application. Our finding suggests that farmers should apply cypermethrin in bean and cauliflower as recommended dose and harvest after 7-10 days for consumer safety.

\section{Acknowledgment}

The authors are grateful to International Science Programme (ISP), Uppsala, Sweden for financial supports.

\section{References}

1. Colume A, S Cardenas, M Gallego, M Valcarcel, 2001. Semiautomatic multiresidue gas chromatographic method for the screening of vegetables for 25 organochlorine \& pyrethroid pesticides. Analytica Chimica Acta, 436 (1), 153-162.
2. Chen ZM and YH Wang, 1996. Chromatographic methods for the determination of pyrethrin and pyrethroid pesticide residues in crops, foods and environmental samples. Journal of Chromatography A, 754(1-2), 367-395.

3. The Pesticide Manual, Fourteenth Edition 2006. Editor: C D S Tomlin, Publisher: BCPC (British Crop Production Council).

4. Fundamental concepts of Environmental Chemistry, G.S. Sodhi, Department of Chemistry, S.G.T.B. Khalsa College, University of Delhi, 2002.

5. Codex Alimentarius, Guidelines on good laboratory practice in pesticide residue analysis CAC/GL40-1993.

6. Chai L. K, N. Mohd-Tahir, H. C. B. Hansen, 2009. Year Pest Management Science, 65 (2), 189-196.

7. Nahar N, M Shoeb, M I R Mamun, S Ahmed, MM Hasan and A Kabir, 2012. Studies of Dissipation Pattern of Cypermethrin in Tomato. Journal of Bangladesh Chemical Society, 25(2), 200-203. 
